\title{
O dispositivo empresarial, a reforma trabalhista e seus embates em enunciados midiáticos
}

\author{
Alyssa Magalhães Prado \\ Universidade Estadual de Minas Gerais, Ituiutaba, MG, Brasil \\ ORCID: https://orcid.org/0000-0002-1144-311X

\section{João Wachelke} \\ Universidade Federal de Uberlândia, Instituto de Psicologia, Uberlândia, MG, Brasil \\ ORCID: https://orcid.org/0000-0003-4364-8598
}

\section{Kátia Menezes de Sousa}

Universidade Federal de Goiás, Faculdade de Letras, Goiânia, GO, Brasil

ORCID: https://orcid.org/0000-0003-3391-2594

\section{Resumo}

Este artigo tem como objetivo problematizar o dispositivo empresarial e seus embates, por meio da análise de enunciados e práticas discursivas veiculadas em jornais brasileiros sobre a reforma trabalhista de 2017. O trabalho se norteou pela questão quanto ao funcionamento desse dispositivo e suas reverberações subjetivas nas relações humanas. O conceito de dispositivo é pensado e utilizado por autores como Foucault, Deleuze e Agamben, para refletir sobre um conjunto de elementos heterogêneos, que envolvem ditos e não ditos, a fim de organizar os jogos saber/poder que circulam socialmente. As contribuições especialmente foucaultianas e de alguns autores que estão se debruçando em estudos sobre o contexto neoliberal deram o aporte teórico-metodológico a pesquisa. 0 processo de triagem do material aconteceu a partir da pesquisa por notícias sobre a reforma trabalhista, selecionando cinco que possuíam como foco principal os empresários. Sendo assim, foi exposto um material de análise contendo algumas instâncias enunciativas e pontuadas algumas interpretações, utilizando, enquanto ferramenta, a análise discursiva foucaultiana. Os enunciados revelam o lugar de protagonismo e referência destinado aos empresários. A criação de supostos embates e lutas estão claras a partir da construção de duas posiçõessujeito: o dos direitos e demandas sociais e o da competitividade e mercado. Em suma, o dispositivo empresarial vai se delineando como protagonista do meio social, enfraquecendo outros dispositivos consolidados, como o jurídico, mas sem 
deixar de suscitar oposições e embates contrários, que podem produzir resistências e novas possibilidades de existência.

\section{Palavras-chave}

Trabalho; Trabalhador; Dispositivo; Empresarial; Jurídico

\section{Introdução}

Esse texto objetiva problematizar a relação do dispositivo empresarial em suas disputas no campo do trabalho, analisando enunciados midiáticos veiculados sobre a modificação na legislação do trabalho e promulgação da Reforma trabalhista no Brasil em 2017. A predileção pela Análise do Discurso foucaultiana (AD) como método de investigação deu-se devido à intenção do estudo por uma reflexão que persiga a proficuidade do funcionamento discursivo nas relações sociais. Algumas questões norteiam esta escrita, como: em um mundo globalizado, onde o capitalismo e neoliberalismo se estabeleceram, pode-se compreender a organização empresarial como um dispositivo? Como o mundo do trabalho, marcado pelas heterogêneas e complexas relações de forças entre os sujeitos, irá se organizar a partir dos discursos ligados a essas formas econômicas? Quais subjetividades são produzidas a partir da legitimação desses discursos?

Segundo Foucault (2008), os autores neoliberais perceberam como economia clássica três categorias fundamentais: terra, capital e trabalho, mas exploraram pouco esta última. Sendo assim, pareceu importante para a nova toada de estudos econômicos realocar o trabalho dentro de suas construções. Diniz e Oliveira (2014) utilizam a interpretação de Fornero (2007) para dizer que Marx, a despeito de destoar do pensamento foucaultiano, devido a sua ideia "macrofísica" do poder presente nas classes dominantes e no Estado, é abordado por Foucault (2008) como um autor indispensável por ter atribuído em seus diagnósticos ao trabalho, ou melhor, à força de trabalho, um protagonismo. Mesmo que os neoliberais recusem o debate de Marx, uma nova abordagem do mundo do trabalho atual será essencial para o novo sujeito econômico ativo que nascerá no tempo contemporâneo, o que será aprofundado adiante.

Peres, Silva e Carvalho (2003) procuraram desenvolver uma leitura do desemprego na cidade de Assis (São Paulo) a partir do Balcão de Empregos da cidade, focada nas demandas que vão se alastrando nas investigações do mundo do trabalho contemporâneo, e, atentos ao crescimento do desemprego, característica das sociedades neoliberais. Alguns 
dados utilizados foram o número de pessoas cadastradas, os cargos mais solicitados, idade, gênero e escolaridade, número total das vagas de emprego disponíveis, pré-requisitos a serem seguidos pelos candidatos e total de vagas ocupadas. 0 estudou identificou uma relação entre o aumento das taxas de desemprego, acarretando no aumento da desigualdade social, e a precarização do campo do trabalho, promovendo vínculos trabalhistas mais suspeitos e informais. Foi possível perceber o sofrimento que a falta da atividade laboral gerava, transformando o Balcão, muitas vezes, em lugar de escuta das angústias daqueles que buscavam se inserir no mercado.

Esse estudo é interessante, pois proporciona uma visão do Brasil em 2003, quando Luiz Inácio Lula da Silva assume a presidência, sendo ele membro e líder de um partido que destaca em seu nome justamente os trabalhadores. Por catorze anos esse partido se manteve na presidência, com dois mandatos de Lula e dois mandatos de Dilma Rousseff, sendo o último interrompido a partir do processo de impeachment que retirou a presidente e alçou seu vice, Michel Temer, em seu lugar. É sob o fantasma desse mesmo desemprego que se fortaleceu um dos argumentos mais sólidos para a mudança na legislação trabalhista brasileira alguns anos mais tarde.

\section{Sobre a Reforma no trabalho}

Em novembro de 2017, o Projeto de Lei n. 13.467 (BRASIL, 2017) foi instaurado no Brasil, modificando profundamente diversos artigos da Consolidação das Leis de Trabalho (CLT). A criação do documento Reforma Trabalhista se relaciona com diversas medidas do governo Temer para lidar com questões sociais e econômicas que assolam o país e sua população. No mundo do trabalho, talvez a questão mais relevante e preocupante para o Estado e população brasileira seja o alto número de desempregados. No início de 2018, alguns dados referentes à situação do trabalho e trabalhadores foram explorados em pesquisas realizadas pelo IBGE (AGÊNCIA IBGE NOTICIAS, 2018). Um alarme é acionado com relação ao desemprego, que atingira seu maior número dos últimos seis anos. Segundo a pesquisa, foi o pior ano para o mercado de trabalho desde 2012, com 13,2 milhões de pessoas desempregadas. Nos últimos três anos, o número de postos de trabalhos, principalmente formalizados, teve uma baixa expressiva, havendo uma perda de 3,3 milhões de trabalhadores com carteira assinada. 
A veiculação de dados como esses atestam que existem dificuldades concretas na geração de empregos. Narrativas semelhantes foram importantes e fortalecedoras na sustentação da defesa de uma Reforma no trabalho, a maior já realizada desde a criação da CLT, em 1943. Porém, apesar de sua rápida aprovação e defesa governamental, alguns movimentos e instituições passaram a problematizar a Reforma trabalhista enquanto solução de melhorias. Carvalho (2017) argumenta que um dos pontos principais da reforma proposta pelo Governo Temer é a sobreposição dos acordos coletivos, ou seja, do negociado, sobre a ação legislativa. Contudo, questiona que o apoio desse processo de flexibilização não é acompanhado de nenhum fortalecimento da parceria coletiva entre trabalhadores, o que implica o enfraquecimento desse grupo perante as negociações com os empregadores.

A flexibilização no mundo do trabalho não é um processo novo aos estudiosos. Filgueiras (2006), ao se debruçar sobre o neoliberalismo brasileiro, afirma que a flexibilização nas relações de trabalho é um dos mecanismos da restruturação produtiva, mecanismo importante para o fortalecimento da expansão do modelo neoliberal, como estratégia de enfraquecimento da coletividade enquanto marca da categoria trabalhador. 0 desemprego seria uma consequência da precarização das condições do trabalho que o modelo gera, com ações como contratos mais informalizados, ampliação das jornadas de trabalho, redução dos incentivos, diminuição e valoração negativa da importância dos sindicatos, entre outros.

Foucault (2008), em uma de suas exposições sobre o mundo contemporâneo, buscou refletir sobre o ordoliberalismo alemão e o neoliberalismo americano, o último tendo se expandido em nível mundial. Para o autor (FOUCAULT, 2008), sustentado por amplas leituras liberais e neoliberais, a economia viveria uma nova "lógica histórica de processo" (FOUCAULT, 2008, p. 305), composta por uma racionalidade interna. 0 trabalho deve ser compreendido não apenas enquanto atividade econômica, mas situado como atividade “aplicada, racionalizada e calculada" (FOUCAULT, 2008, p. 307) por aquele que trabalha. A economia passa a existir a partir de "unidades-empresa" (FOUCAULT, 2008, p. 310), e o trabalhador como máquina, interpretado com significado positivo, aquele que produzirá os fluxos de renda na sociedade. 0 homo oeconomicus, se anteriormente era entendido como um dos lados no processo de trocas, na perspectiva neoliberal será o empresário, um empresário de si mesmo, aquele que será, ao mesmo tempo, seu próprio capital, sua fonte de renda e seu produtor. Nesse contexto, seria construída uma tecnologia neoliberal de governo, a qual regeria, no meio social, processos como mercado e concorrência. 
Percebe-se que Foucault (2008) já anuncia postulados para problemas que ficaram explícitos anos depois. Sendo assim, alguns autores, como os que serão apresentados a seguir, a partir de alguns de seus conceitos, partirão para uma análise do neoliberalismo no século XXI. Em A nova razão do mundo: Ensaio sobre a sociedade neoliberal, Dardot e Laval (2016) abordam o neoliberalismo, ampliando a discussão sobre o modelo para além das análises mais sociológicas e econômicas, pensando-o como uma nova racionalidade mundial que se finca nos processos de produção subjetiva dos sujeitos, indo além de uma ideologia, modelo ou continuidade do liberalismo. No contexto da tese desenvolvida pelos autores, opta-se aqui por acentuar as postulações ligadas ao governo empresarial, de maior pertinência para o presente trabalho.

O Estado muito foi relacionado ao conceito de soberania, instância máxima na regulação de um conjunto de medidas que visariam integrar o conjunto social e suas demandas. 0 que o neoliberalismo provoca é o Estado se relacionando fortemente ao conceito de governança, em que a norma da concorrência passa a ser primordial. Mas o que essa mudança de nomenclatura implica na prática? Implica o Estado governando a fim de maximizar seus ganhos, da mesma forma que pensa a gerência de uma empresa. Se historicamente o papel estatal ao se falar em liberalismo foi muito associado à minimização de sua finalidade, no neoliberalismo, não se trata de um papel menor, mas da submissão do Estado (DARDOT; LAVAL, 2016).

As agendas, ou seja, as prioridades do Estado passam a ser as urgências do mercado, e as demandas sociais são culpabilizadas quando crises se desencadeiam. Após esses acontecimentos, a ordem neoliberal arquiteta o desmantelamento do Estado social e educacional, direcionando a eles a lógica da concorrência e competitividade. Desse ideal partem as grandes reformas, segundo Dardot e Laval (2016), que acabarão por degradar as condições dos sujeitos, para a conveniência da eficácia e bom desempenho dos oligopólios. 0 que se corrobora no Estado irá se relacionar intimamente com a produção subjetiva dos indivíduos, regendo suas vidas e relações também como empresas, empreendendo e competindo constantemente, legitimando o neoliberalismo enquanto racionalidade.

É dessa reflexão previamente construída que parece possível pensar a empresa enquanto um organizador, uma rede que conecta as relações e que será indispensável na regulação social e subjetiva da sociedade. Mas por muitas vezes seu papel parece nebuloso, como conota a expressão a mão invisível do mercado. Será que ela é de fato invisível? Se pensarmos na Reforma e nos discursos que a sustentam, seria possível observar como se 
relacionam os elementos que a constroem, constituem e institucionalizam, pensando essa concepção neoliberal e, mais importante, empresarial?

Conforme o interesse se orientando para a análise dos discursos e feixes de relações constituintes do empresariado e do documento da Reforma trabalhista, as perspectivas foucaultianas manifestam-se como possibilidades frutíferas para o pensamento crítico e político. Dessa forma, a seguir, algumas explicações conceituais e esclarecimentos sobre o dispositivo e suas potenciais contribuições a essa investigação serão apresentados.

\section{Práticas discursivas e a concepção de dispositivo}

Em entrevista dada por Foucault (2003), o autor define o dispositivo como um grupo diversificado que contém “[...] discursos, instituições, organizações arquitetônicas, decisões regulamentares, medidas administrativas, enunciados científicos, proposições filosóficas, morais filantrópicas [...]" (FOUCAULT, 2003, p. 138). Portanto, o dispositivo é compreendido como rede, à medida que articula as relações entre ditos e não ditos. Essa rede pode encontrar no discurso, nas construções relacionais, um componente que irá fortalecer ou encobrir práticas antes silenciadas; também é capaz de produzir novos sentidos para essa prática, entendendo-se que se estabelecem relações como num jogo. Além disso, o dispositivo irrompe, em dado momento histórico, para responder alguma urgência, sendolhe atribuído um lugar de estratégia para a dominação. A construção que Foucault (2003) realiza sobre rede aproxima-se da noção e compreensão da história que desenvolve ao longo de seus estudos, sendo ela colocada como um movimento descontínuo, fragmentado, sustentando um entendimento em que, em meio a esse movimento, ainda é possível identificar regularidades (CARVALHO; SARGENTINI, 2014).

0 dispositivo está sempre registrado nos jogos de poder, acoplado às formações do saber que dali se enraízam, mas que também o retém. Assim, nas palavras do autor, argumenta-se o dispositivo enquanto “ [...] estratégias de relações de força sustentando tipos de saber e sendo sustentadas por eles [...]" (FOUCAULT, 2003, p. 139).

Como o discurso e a história tiveram destaque na conceituação de dispositivo formulada por Foucault (2003), o autor e o parceiro de estudos Paul Veyne (2011) explica o discurso na literatura foucaultiana enquanto:

[...] a descrição mais precisa, mais concisa de uma formação histórica em sua nudez, é a atualização de sua última diferença individual. Ir assim até a 
diferença última de uma singularidade datada exige um esforço intelectual de apercepção: é preciso despojar o acontecimento dos drapeados demasiados amplos que o banalizam e racionalizam (VEYNE, 2011, p. 1617).

O que Veyne (2011) explicita é o processo arqueogenealógico foucaultiano, em que o filósofo, interessado na sustentação do que se diz, busca os efeitos produzidos pelos lugares de falas nos ditos, para compreender as técnicas de objetivação, as lutas pelo poder, as práticas de subjetivação. Esse exercício não produz a busca pelas origens, mas pelas emergências, partindo das superfícies nas quais se inscrevem os acontecimentos. Essas investigações acontecerão pela singularidade dos acontecimentos por meio de enunciados adormecidos, levantando a questão sobre o que permitiu a emergência de certos discursos ou suas novas configurações. Essa conduta de análise acarreta em uma postura ética e de resistência, ao realizar a crítica do que está posto e pôr em visibilidade conexões anteriormente fora da luminosidade (FOUCAULT, 2010).

Retomando as contribuições sobre o dispositivo, dois outros autores complementarão o raciocínio foucaultiano. Deleuze (2005) define o dispositivo como um complexo de linhas (em um sentido próximo da rede de Foucault) de diferentes naturezas. Essas linhas são marcadas pelo desequilíbrio, que provoca movimentos de aproximação e afastamento. $O$ autor (DELEUZE, 2005) realça as três grandes instâncias do trabalho de Foucault (saber, poder, subjetividade) como nunca definidas por delineados fixos, mas em constantes tensões, já que, no trabalho foucaultiano, é mediante as crises que se torna possível a descoberta de novas linhas. Essas linhas possibilitarão os vínculos enunciativos, as ligações entre as formações discursivas e a sistematização dos arquivos, compreendidos enquanto a história, retrato do que somos e deixamos de ser. A presença da história nos dispositivos, segundo a abordagem deleuziana, advém dos regimes de visibilidade e enunciação. As construções históricas se realizam a partir do não visto e não dito, estando aí a importância dos discursos, que funcionam via dispositivos como uma linha distinta na articulação entre passado e futuro (CARVALHO; SARGENTINI, 2014).

Agamben (2009) sintetiza os dispositivos em três tópicos:

a. É um conjunto heterogêneo, linguístico e não linguístico, que inclui virtualmente qualquer coisa no mesmo título: discursos, instituições, edifícios, leis, medidas de política, proposições filosóficas etc. 0 dispositivo em si mesmo é a rede que estabelece entre esses elementos. 
b. 0 dispositivo tem sempre uma função estratégica concreta e se inscreve sempre numa relação de poder.

c. Como tal, resulta do cruzamento de relações de poder e de relações de saber (AGAMBEN, 2009, p. 26).

Devido ao forte interesse de Agamben (2009) por esmiuçar o momento contemporâneo, o autor focaliza os dispositivos atuais, entendendo que eles se inflacionam no momento, compreendendo o dispositivo como tudo que possui capacidade de captar, regular, orientar, modelar, controlar e certificar as opiniões, posições, ações, gestos e discursos dos sujeitos. Dessa forma, o entendimento sobre os dispositivos, bastante ligados ao poder, se amplia das disciplinas, prisões, escolas, manicômios, instituições, para coisas comuns como um lápis, os escritos, a literatura, o cigarro, o celular, até mesmo a linguagem, citada pelo autor (AGAMBEN, 2009) como o mais antigo dos dispositivos, pois, há milhares de anos atrás, apreendeu um primata.

Agamben (2009) relaciona o dispositivo com a produção de subjetividades, ao afirmar que o aumento excessivo dos dispositivos na conjuntura contemporânea implica uma multiplicação de modos de subjetivação, enfraquecendo a subjetividade, não a anulando, mas conferindo a ela alto valor de mascaramento. Com base nisso, o teórico afirma que as sociedades atuais estabelecerão não a produção de subjetividades, mas a dessubjetivação de corpos que não sustentam nenhum processo subjetivador. 0 autor (AGAMBEN, 2009) complementa que, apesar dessa dificuldade de se implicar em um processo de subjetivação, na matriz do dispositivo há o desejo verdadeiramente humano por felicidade, sendo essa a grande potência do dispositivo.

Dispositivo pode ser enxergado então como um organizador, que irá ampliar o modo de interpretação do analista na leitura do seu objeto. São nas tensões que iremos trabalhar. Os conflitos e crises que passam muitas vezes desapercebidos serão material para se poder compreender os caminhos das mudanças concretas. A potência da análise vai além de apontar um problema; caminhará na construção de como os processos vão se individualizando e se instituindo mutuamente.

Mas por que eleger o dispositivo no presente estudo? Optou-se por esse conceito nesta elaboração, interpretando sua reflexão como importante para se pensar processos contemporâneos e de impacto social e cultural. Nas práticas políticas da atualidade, universaliza-se um discurso, até mesmo legitimando-o no campo jurídico, como é o caso da Reforma trabalhista, instaurando-se uma generalização positiva sobre sua aplicabilidade. 
Isso abrange as relações saber/poder e produção de subjetividades sobre aqueles que terão suas vidas atravessadas por esse discurso, no caso, todos os trabalhadores e também nãotrabalhadores, como no ocorrido com os desempregados. 0 dispositivo instrumentaliza o pensamento acerca das redes que estarão provendo esses discursos e suas consequentes ocorrências.

Visando fortalecer o conceito do dispositivo, e pensando que a análise de conflitos no campo do trabalho expressa forte caráter político, outro pressuposto importante do trabalho foucaultiano é a governamentalidade. Foucault (2003), em seu trabalho histórico, mapeou, a partir de uma investigação dos saberes, enunciados postos enquanto verdades absolutas para entender e chegar a rede de "micro-poderes" que estarão presentes nos arredores da sociedade. Nesse processo, investigou o poder soberano, tecnologia de poder absoluta onde o soberano decide sobre a vida dos subordinados, sendo que a lei é o instrumento principal e o território é o elemento a ser mantido; e o poder disciplinar, tecnologia de poder que se instrumentaliza a partir das disciplinas que atravessam todo o corpo social por meio da vigilância e punição como suas principais ferramentas. Observa-se que, se anteriormente, no poder soberano, o exercício do poder acontecia por meio do Estado, no poder disciplinar ele ocorre via docilização dos corpos. O sujeito passa a existir e não é mais dominado e reprimido, mas sim útil e dócil (DINIZ; OLIVEIRA, 2014).

Muitos dos trabalhos clássicos de Foucault (2003) tratarão justamente do exercício conhecido enquanto poder disciplinar, institucionalizado na Europa a partir do século XVIII. Esse contexto insere um outro processo conhecido como biopoder que, por conseguinte, resultará na biopolítica. 0 biopoder se concentrará no controle das massas. Seria um modo de apresentar o poder não somente no universo individualizado do sujeito, mas também no universo da população, inteirado nos processos coletivos. Ele surge como forma de proteção e segurança, preocupado com tudo aquilo que intimide a população, sendo o dispositivo disciplinar endereçado ao "homem-corpo" e o biopoder ao "homem-espécie" (DINIZ; OLIVEIRA, 2014). Foucault (2003) evidencia a população enquanto o objetivo final do governo, chegando então no que ele chamou de governamentalidade. Para o autor (FOUCAULT, 2003), governar é governar as coisas. A arte de governar implica no governo de si mesmo e dos outros, e a atividade consistirá na articulação de estratégias e táticas para compreender o que compete ou não ao Estado, o que é público ou privado, levando as técnicas de governo a serem definidas enquanto uma questão política primordial. 
Dardot e Laval (2016), apoiados no pensamento de Foucault (2003), afirmam que a governamentalidade neoliberal irá se amparar em um quadro normativo global, norteado pela premissa máxima da liberdade e artimanhas no campo individual, determinará ações, práticas e escolhas originais. 0 neoliberalismo inaugurará técnicas de poder inovadoras sobre os acontecimentos e subjetividades (DARDOT; LAVAL, 2016).

Cabe então o processo de provocação, reflexão, rachaduras e penetração nos enunciados que sustentam as redes informacionais sobre o acontecimento, visando alcançar a rede de elementos que apoiam a emergência de certos discursos. Assim, os sujeitos, aqueles que resultam dessas relações, poderão ressignificar processamentos constitutivos e repensar modos de ser e estar no mundo.

Em suma, essas conceituações serão retomadas a partir de um material a ser melhor dissecado. A seguir, estão expostos alguns ditos, veiculados em instâncias jornalísticas de forte impacto nacional, sobre o empresariado e suas concepções e insinuações sobre a Reforma no trabalho.

\section{A análise do dispositivo empresarial em enunciados sobre a Reforma}

Interessando-se pela indagação do que comporta o dispositivo empresarial, alguns enunciados foram separados para seguir com uma análise discursiva sobre as redes de elementos que estão ali integrados. 0 material selecionado faz parte do discurso informativo via enunciados midiáticos. A opção foi realizada a partir do escopo teórico que entende que a mídia possui grande relação não apenas com o imaginário do saber, mas também com o imaginário do poder, em razão da competência que é atribuída a esses veículos. Todo veículo de informação, necessariamente, desempenha um poder sobre o destinatário, sendo o complexo coletivo das mídias detentor de uma fração do poder social. Para Charaudeau (2006), a verdade não estará presente no discurso, mas sim, no efeito que ele produzirá e é esse efeito que, por meio da análise do discurso foucaultiana, queremos investigar. Isto posto, “ [...] o discurso de informação midiática joga com essa influência, pondo em cena, de maneira variável e com consequências diversas, efeitos de autenticidade, de verossimilhança e de dramatização [...]" (CHARAUDEAU, 2006, p. 63).

Segundo Foucault (1999), a ordem que ampara a circulação dos discursos é produzida através da dominação, da seleção, organização e redistribuição de uma série de técnicas cuja função é fazer insurgir poderes e ameaças, controlar a dinâmica dos 
acontecimentos e desviar sua concretude. Não somente isso, como também deverá o analista se atentar justamente às entranhas das relações construídas em torno dessa ordem operada no âmbito discursivo. 0 olhar para a definição do corpus priorizou os atravessamentos do dispositivo empresarial nas construções discursivas ligadas à Reforma do trabalho brasileiro. Dessa forma, o corpus selecionado contém cinco notícias, são elas:

a) Empresários comemoram aprovação da reforma trabalhista (PEREIRA, 2017), retirado da revista Exame;

b) Veja o que muda para empresários e empregados com a reforma trabalhista (PERRIN, 2017), retirado do jornal Folha de São Paulo;

c) Empresários reagem a críticas da OIT à reforma trabalhista (EMPRESÁRIOS, 2018), retirado do jornal Correio Braziliense;

d) Reforma trabalhista: o que muda para os micro e pequenos empresários (DINIZ, 2017), retirado do jornal 0 Globo;

e) Empresários do Estado comemoram aprovação da reforma trabalhista (EMPRESÁRIOS, 2017), retirado da Gazeta online.

Primeiramente, chama a atenção como diversos jornais forneceram especial espaço à categoria dos empresários. Se anteriormente, ao se pensar na história do trabalho e do próprio documento da CLT, comumente se nomeava quem ofertava a atividade laboral como patrão ou empregador, agora os empresários tomam a cena como o sujeito que detém esse poder. Esse novo lugar já configura uma nova produção subjetiva contemporânea que ganha visibilidade e impacto social e econômico. Quando o jornalista opta por destinar ou referenciar destaque à nomenclatura empresários, sinaliza elementos importantes para o pensamento em torno dos interesses envolvidos no projeto de lei em questão, pois providencia aos interesses do grupo lugar de destaque e relevância social.

As construções discursivas direcionam o leitor para a existência de um problema relevante, uma inevitabilidade que orientou a criação deste documento e projeto de lei. As reportagens buscam sustentar que existe uma perturbação e que esta deve ser solucionada; assim, o único caminho possível seria a modificação da legislação atual, cunhada enquanto ultrapassada e em descompasso com o atual mundo do trabalho. Essa seria a ameaça que os discursos vão desenhando; no caso, a urgência do desemprego aparece e a solução se torna um novo modo de (des)regular o trabalho. Nesse processo, alguns atores têm a palavra e, de 
certo modo, são mais escutados que outros, ainda que as notícias como um todo busquem apresentar visões contrárias, a fim de apresentar diferentes pontos de vista.

Os enunciados contam um pouco da dinâmica que se cria sobre a iminente aplicação do projeto de lei. A sustentação do documento vem no discurso político estatal e empresarial, como pode ser visto a seguir.

A aprovação da reforma trabalhista, ontem, no Senado Federal, foi, na opinião de representantes da iniciativa privada, uma vitória para o setor produtivo brasileiro, que há anos tenta mudar as leis nacionais. Para os empresários, a reforma é o início de um caminho de modernização das relações de trabalho que o País começa a trilhar e que trará maior competitividade para as empresas nacionais. [...] a reforma trabalhista era uma necessidade para devolver a competitividade ao País. (PEREIRA, 2017)

0 texto está pronto para ser sancionado pelo presidente. A vitória na aprovação de uma das principais bandeiras do governo foi um alívio para o peemedebista em meio à crise política deflagrada pela delação da JBS e que levou Temer a ser denunciado por corrupção pela Procuradoria-Geral da República. [...] Para empresários, a reforma moderniza a legislação trabalhista ao promover maior flexibilidade nas modalidades de contratação e demissão, assim como ao dar mais poder para a negociação entre sindicato e empresa, que poderão a partir de agora se sobrepor à CLT. (PERRIN, 2017, grifo nosso).

Em sua opinião [Everton Generoso, diretor de Negócios do Grupo InsigneAudiplanus, especialista em contabilidade], as mudanças trazem grande incentivo econômico para o empreendedorismo, que levará à abertura de mais vagas de emprego e de aumento no consumo. (DINIZ, 2017, grifo nosso).

Para a classe empresarial, as novas regras vão trazer mais segurança jurídica, flexibilizar as relações de trabalho, reduzir os impasses entre patrões e empregados na Justiça, aumentar a formalidade, gerar mais empregos e ainda contribuir para a recuperação da economia brasileira. [...] 0 presidente da Federação das Indústrias do Espírito Santo (Findes), Marcos Guerra, destaca que o texto inova a forma de gerar emprego. 'A modernização da lei amplia a possibilidade do capital e do trabalho se aproximarem mais sem a necessidade de cumprirem uma CLT (Consolidação das Leis do Trabalho) que é da década de 1940 e está ultrapassada.' (EMPRESÁRIOS..., 2017, grifo nosso).

Os grifos realizados durante a análise do material exteriorizam as representações da classe empresarial, que vão entender como positivas as consequências que virão do projeto de lei, como aumento da competitividade, maior flexibilidade nos contratos, crescimento de empregos, empreendedorismo, menos impasses nas relações, além de identificarem o projeto enquanto uma modernização. É possível perceber, em itálico, marcas linguísticas 
que apontam uma caracterização de vitoriosos, destinada pelo sujeito jornalista aos empresários e ao grupo político representado pelo presidente Michel Temer. Palavras como necessidade, modernização, inovação, segurança também sinalizam lugares estratégicos de fala, onde se caracteriza positivamente a existência do documento. 0 uso desses termos caracteriza uma tática do dispositivo empresarial para apresentar ao leitor o quanto são positivas as mudanças, ainda que essas não estejam integralmente aplicadas no contexto social.

Especialmente retomando Deleuze (2005), é simbólica esta vinculação, já que é, em meio aos tensionamentos e conflitos advindos das linhas de força que compõem os dispositivos, que o poder inflama e tece a rede de elementos que irá se irromper nas disputas. Desse modo, essas marcas afirmam o lugar de convencimento que a Reforma tenta conquistar socialmente, evidenciando o empresário e silenciando o trabalhador comum e suas percepções sobre as mudanças, sem citação direta de seu posicionamento.

Onde estariam então os perdedores? Algumas notícias revelam esses atores em enunciados logo abaixo:

Para sindicatos e associações de juízes, procuradores e advogados do trabalho, a reforma leva à precarização do mercado de trabalho ao aumentar a insegurança de profissionais e retirar direitos estabelecidos na CLT. Eles afirmam também que o projeto tem uma série de previsões inconstitucionais. (PERRIN, 2017).

Na semana passada, a OIT incluiu o Brasil na lista dos 24 casos considerados como mais graves de suspeitas de violações de direitos trabalhistas pela Comissão de Normas por dúvidas envolvendo a reforma trabalhista, principalmente, as negociações coletivas. 0 foco das críticas está na Convenção 98 da OIT. (EMPRESÁRIOS..., 2018).

O presidente da Associação Nacional dos Magistrados da Justiça do Trabalho (Anamatra), Guilherme Feliciano, considera que há muitos pontos controversos no texto, desde a tramitação. (DINIZ, 2017).

A nova legislação trabalhista aprovada no Senado e que agora segue para sanção presidencial é vista pelas centrais sindicais como um 'desmonte dos direitos do trabalhador' (EMPRESÁRIOS..., 2017).

Em itálico, estão alguns atores, críticos e atentos aos interesses da reforma; sublinhado, estão as sequências enunciativas que representam questionamentos e problematizações. Nas marcas linguísticas, destacam-se palavras como precarização, insegurança, inconstitucional, violações, controverso, desmonte para demarcar o lugar de contestação e crítica que se faz a institucionalização dessa nova regulação. 
Amparando-se na concepção foucaultiana, pode-se perceber o embate no encontro dos discursos, ficando explícitas as relações opositivas que vão se formando ao redor do acontecimento reforma trabalhista. Essas lutas, apesar de se configurarem no entorno da atualidade, são sócio-históricas, à medida que uma investigação aprofundada pode apresentar o quanto o trabalho no Brasil é perpassado pelos embates no campo social, político e econômico, não somente, pelas desigualdades, já que, como afirma Carvalho (2017), o direito do trabalho possui como marca o reconhecimento da desigualdade no embate das forças.

É perceptível a polarização realizada nas notícias sobre aqueles que defendem e aqueles que se opõem a Reforma. Os enunciados são sempre construídos de modo a dar voz aos defensores e aos críticos e, de certa forma, convocando o leitor a uma tomada de posição. Assim, os projetos políticos estão na mesa, e o sujeito deve escolher um ou outro. Se pensarmos no contexto atual, há ênfase do termo polarização nos últimos anos. 0 modo como as notícias sobre a Reforma estão sendo construídas demonstram que os enunciados refletem como vêm acontecendo as relações sociais cotidianas e a dificuldade de visualizar o outro enquanto sujeito heterogêneo e não somente enquanto um grupo com uma posição, logo, grupo homogêneo e uniforme.

Há um dispositivo em especial que seria interessante contrapor ao empresarial. Faria (2004) observa que a Constituição de 1988 colocou de vez juízes e promotores em evidência na vida econômica e administrativa do país. Há algum tempo, profissionais, em especial das ciências humanas, utilizam a nomenclatura judicialização da vida para abordar as formas como o Judiciário vai se enraizando para além das leis, de forma a se fincar nos modos de ser e se relacionar no mundo. Na política, os escândalos ligados à corrupção transformaram nomes como Joaquim Barbosa e Sérgio Moro em heróis nacionais, com aclamados pedidos pela entrada destes na vida política.

Mas por que isso é relevante para a presente discussão? Se a tendência no campo político-social parece ser a exaltação desses agentes da justiça, no mundo do trabalho, a história parece seguir uma toada diferente. Como Carvalho (2017) coloca, o Direito do trabalho existe a partir da premissa de lados desiguais, onde o trabalhador representa um lado desfavorecido. Por isso, o papel desse ramo jurídico é justamente regulamentar e promover uma resolução dos conflitos mais igualitária. Mas parece ser com isso que a nova Reforma do trabalho procura romper, quando fortalece o dispositivo empresarial e enfraquece, além de confundir, o dispositivo jurídico. 
Diversos enunciados de sujeitos, como advogados, ou ligados à Justiça do trabalho, ou citando a instabilidade jurídica, emergem e surgem como questionamento da relação entre as relações de forças entre o empresarial e o jurídico. Seguindo nessa direção, a ordem do discurso jurídico se apresenta de suma importância para refletir nesse sentido. Segundo Perucchi e Toneli (2008), calcadas nas contribuições de Michel Foucault,

\begin{abstract}
As práticas judiciárias, como tantas outras, são constituídas por práticas de exercício do poder que se sustentam a partir de determinados discursos que lhes conferem estatuto de verdade. Esses regimes de poder constituem as instituições, atravessam a vida cotidiana e as diversas esferas sociais. Trata-se de um poder produtivo, que constrói sujeitos, normalizando suas condutas e condicionando suas práticas aos regimes de verdade estabelecidos por dispositivos de poder e de saber. A jurisprudência, como fonte do Direito, é um dispositivo que configura seus vetores de força nas redes discursivas da norma jurídica. 0 código legal que a jurisprudência enuncia define as condutas, identifica o sujeito; o código atravessa a subjetividade. A pessoa é reconhecida pelo código legal que define um lugar, uma posição a ser ocupada nos diferentes níveis de reconhecimento no contexto jurídico. (PERUCCHI; TONELI, 2008, p. 141).
\end{abstract}

O pensamento sobre as práticas judiciárias é importante, visto que uma reforma no trabalho tão impactante como a realizada, que modificou cerca de mais de 100 artigos e parágrafos, se relaciona intimamente com as ações jurídicas, colocadas de certo modo em segundo plano, quando o negociado prevalece sobre o legislado. Pode-se refletir que as novas formulações na organização trabalhista enfraqueceriam o dispositivo da jurisprudência, tratando como novo protagonista agora o dispositivo empresarial.

Todavia, as práticas não são tão simples, já que não se trata apenas de substituir um pelo outro. Os dispositivos coexistem e isso fica explícito quando a luta dos favoráveis à Reforma consiste justamente na legalização dela. Isto é, o dispositivo empresarial não busca simplesmente anular e substituir o dispositivo jurídico; ele intenta que esse dispositivo valide sua proposta e sua existência, destinando a ele o direito de decidir fora do Direito. Dessa forma, é a conquista do dispositivo empresarial sobre parte do campo jurídico, materializando concretamente o embate entre eles.

É possível ter um panorama do campo de embates em que se configuram as relações de trabalho em que, atualmente, os empresários prevalecem literalmente sobre os agentes da justiça e lei. A Reforma pode ser compreendida então como mecanismo neoliberal relevante, pois interfere de modo direto na forma como se relacionam e disputam o poder no meio social e econômico brasileiro. 
Não somente isso, mas é também função estratégica e política sua aprovação. Como fica explícito nas notícias, a Reforma foi uma grande vitória para um governo que começava a ver explodir denúncias sobre corrupção, principalmente de sua figura central, o Presidente da República. A promulgação de um documento que propicia benefícios e responde a interesses de certos grupos fortalece a autoridade e distrai a população na construção de enunciados que prometem a solução para o desemprego.

As produções sobre sujeitos vão se delineando na mídia de forma antagônica. 0 sujeito da competitividade, guiado pelo empreendedorismo, pela conquista sobre a ordem jurídica e conduzido pelas leis do mercado contra o sujeito dos direitos, que verbaliza precariedade, violações, insegurança. Ambos serão objetivados pelo modo como o sujeito jornalista constrói e ordena os enunciados, direcionando ao outro um caráter negativo. Retomando Dardot e Laval (2016), suas postulações são de grande contribuição para reflexão sobre como a construção neoliberal valida os discursos e é também validada por eles. A grande mídia se ordena no entorno das expectativas empresariais, delegando um estatuto de saber/poder sobre o que seria melhor no mundo do trabalho. Não devemos esquecer que essa mídia, apesar de se pautar em temas do campo público, faz parte em grande escala de um conjunto de empresas privadas, que defenderá seus interesses (FONSECA, 2011). A CLT, resultado de uma série de demandas históricas, se torna insignificante e ultrapassada, pois o novo, o moderno, se funda a partir de um governo atento ao e arquitetado para o mercado produtivo e ao/para o empresariado local e mundial.

Se a grande questão que norteia este trabalho foi o dispositivo, então o que se pode dizer de sua presença nesse estudo, afinal? 0 dispositivo empresarial é recheado de elementos que organizam sua racionalidade interna, ficando explícito o lugar de poder que os discursos em voga representam na relação com as instâncias. Sustentados por formulações que irão caminhar na construção de verdades como a defesa do mercado, da competitividade, do empreendedorismo, esse saber será base para as defesas dos interesses mercantis. Em consonância com esse saber, instauram-se jogos de poder no sentido de consolidar ainda mais a ordem do discurso neoliberal, produzindo sujeitos subjetivados pelo pilar da competição.

Apesar da relação feita mais diretamente entre o dispositivo empresarial e o jurídico, outros grupos podem ser convocados a uma breve reflexão. Os sindicatos, que seriam a organização representativa dos trabalhadores, são sempre citados nas notícias 
como contrários às mudanças, demarcando, ainda hoje influência, quando possuem sua voz ouvida nos noticiários. É possível problematizar se o tom de seu discurso se articula com o dos trabalhadores, ou se os trabalhadores atualmente podem estar falando por outros veículos, como por exemplo as redes sociais. Desse pensamento podem ser cogitados outros dispositivos que batalhariam nesse espaço, como grupos de movimentos expressivos em redes sociais que vão se configurando como reais disseminadores de opinião.

A população foi definida por Foucault (2003) como o objetivo final do governo das condutas, e esse parece estar sendo realizado pelas empresas. Se não há empregos circulado como o maior problema atual - não é devido a falhas do governo e Estado, mas sim por causa das dificuldades do setor empresarial. Porém, ao mesmo tempo que o discurso do Estado mínimo se fortalece, vivemos um período em que empresários buscam ascender em papéis políticos como o caso de Donald Trump nos Estados Unidos e João Dória no Brasil. 0 desejo de governar a conduta dos homens está presente no dispositivo empresarial, estimulando as táticas ligadas a concorrência e a valorização do mercado. Adicionaria além dessas também, enquanto tática, a estratégia de oposição, observada nos enunciados, como ferramenta para estimular uma situação de nós contra eles que favorece que o cenário se construa a partir de narrativas como: você ficará do lado do moderno ou do ultrapassado? E essa escolha, quando feita, determina quem você é e quem você representa. Infelizmente, passa-se por um período no cenário brasileiro em que sujeitos se tornam, de modo simplista e uniforme, um composto de um grupo que está em oposição ao outro grupo, cada um definido a partir dos projetos políticos por que optam. Sendo assim, o dispositivo empresarial joga centrado nos pilares neoliberais: concorrência, mercado, individualismo e principalmente, liberdades. Como alguém seria contra a premissa da liberdade? 0 dispositivo joga com essa escolha, quando questiona em enunciados midiáticos o que seria melhor: regulamentação, que permite ao trabalhador liberdades e flexibilidade ou regulamentação, que estabelece burocratização e parasitismo Estatal.

Para finalizar, retoma-se novamente Foucault (2004), em particular, uma entrevista conferida por ele, intitulada Uma estética da existência. Quando questionado se seria possível existir verdade na política, o autor responde que é sim praticável reivindicar aos que governam a parresía (palavra franca), historicamente atrelada à coragem da verdade, nas táticas governamentais, nos projetos de governo, nas ações e discursos políticos, produzindo sentidos nas tomadas de condutas e escolhas, em nome do conhecimento, da experiência e da vivência de sujeito cidadão. Da vontade de se constituir enquanto sujeito 
em busca da ética, provém a compreensão do funcionamento dos jogos de dominação e opressão, transparecendo novas possibilidades de se fazer e criar novos modos de existir (FOUCAULT, 2004).

\section{Considerações finais}

A presente elaboração versou sobre a relevância do conceito de dispositivo - além de outros desenvolvimentos dos textos foucaultianos, para se pensar na organização empresarial e os discursos que a atravessam. A noção, articulada a diversos outros elementos da ampla e sólida obra de Michel Foucault, forneceram ferramenta importante para pensar como os acontecimentos não são isolados, nem desmembrados, a partir da retomada de alguns conceitos e jogos de saber/poder que estão historicamente se consolidando.

As análises das práticas discursivas foram potentes na procura por apreender como os sujeitos repercutem nos veículos de mídia, em particular, associados às reformas no mundo do trabalho. Este recorte sugestiona a importância do diagnóstico social e contemporâneo, tendo em vista que a Reforma trabalhista é um acontecimento de caráter fortemente ético-político, que reverbera de modo concreto e subjetivo nas vidas de todos os brasileiros e brasileiras. Os enunciados destacados permitiram uma reflexão acerca das principais estratégias do dispositivo empresarial, marcado, principalmente, pelos pilares da competitividade e concorrência, mas também pela promessa de liberdades aos sujeitos, e defendido pela grande mídia que cobra do leitor uma tomada de posição. 0 dispositivo empresarial demonstra também que vem conquistando seu lugar, quando se sobrepõe ao campo jurídico e opera de modo a valorizar negativamente as organizações dos trabalhadores e suas possibilidades enquanto coletivo, individualizando e isolando os sujeitos.

O jornalista, sujeito que opera via linguagem as práticas discursivas, veicula as oposições direcionadas pela ordem do discurso neoliberal, dando destaque e antagonizando os enunciados referentes aos direitos humanos e demandas sociais. Há um regime de visibilidade para as novas formas de se constituir relações, pautadas pelo competitivo, pelo moderno. Ficam para trás aqueles que não aceitam, que insistem em se agarrar à velha legislação e, consequentemente, à velha produção de sujeito. 0 novo é selvagem e vitorioso, enquanto o antigo reluta, com parcos recursos que tem, para construir práticas de 
resistências. A ética de si e a criatividade aparecem enquanto elementos energéticos para constituições singulares insurgentes.

\section{Financiamento}

Este trabalho obteve financiamento da Coordenação de Aperfeiçoamento de Pessoal de Nível Superior (CAPES).

\section{Referências}

AGAMBEN, Giorgio. 0 que é um dispositivo? In: AGAMBEN, Giorgio. 0 que é o contemporâneo? E outros ensaios. Chapecó: Argos, 2009. p. 25-51.

AGÊNCIA IBGE NOTICIAS. Desemprego recua em dezembro, mas taxa média do ano é a maior desde 2012. Rio de Janeiro: IBGE, 9 jan. 2018.

BRASIL. Lei $\mathrm{n}^{\circ}$ 13.467, de 13 de julho de 2017. Altera a Consolidação das Leis do Trabalho (CLT), aprovada pelo Decreto-Lei $n^{\circ} 5.452$, de $1^{\circ}$ de maio de 1943 , e as Leis $n^{\circ} 6.019$, de 3 de janeiro de 1974, 8.036, de 11 de maio de 1990, e 8.212, de 24 de julho de 1991, a fim de adequar a legislação às novas relações de trabalho. Diário Oficial [da] União, Brasília, DF, 14 jul. 2014.

CARVALHO, Sandro Sancchet de. Uma visão geral sobre a reforma trabalhista. Mercado de trabalho, Brasília, n. 63, p. 81-94, 2017.

CARVALHO, Pedro Henrique Varoni de; SARGENTINI, Vanice Maria Oliveira. Dispositivo, discurso e produção de subjetividades. In: FERNANDES JÚNIOR, Antônio; SOUSA, Kátia Menezes de (org.). Dispositivos de poder em Foucault: práticas e discursos da atualidade. Goiânia: Gráfica da UFG, 2014.

CHARAUDEAU, Patrick. Discurso das mídias. São Paulo: Contexto, 2006.

DARDOT, Pierre; LAVAL, Christian. A nova razão do mundo: ensaio sobre a sociedade neoliberal. São Paulo: Boitempo, 2016.

DELEUZE, Gilles. 0 que é um dispositivo? In: DELEUZE, Gilles. 0 mistério de Ariana. Lisboa: Vega, 2005. p. 83-96.

DINIZ, Ana Carolina. Reforma trabalhista: o que muda para os micro e pequenos empresários. 0 Globo, Rio de Janeiro, 19 nov. 2017.

DINIZ, Francisco Rômulo Alves; OLIVEIRA, Almeida Alves de. Foucault: do poder disciplinar ao biopoder. Scientia, Sobral, v. 2, n. 3, p. 143-158, 2014. 
EMPRESÁRIOS reagem a críticas da OIT à reforma trabalhista. Correio Braziliense, Brasília, 5 jun. 2018.

EMPRESÁRIOS do Estado comemoram aprovação da reforma trabalhista. Gazeta Online, Vitória, 12 jul. 2017.

FARIA, José Eduardo. 0 sistema brasileiro de Justiça: experiência recente e futuros desafios. Estudos Avançados, São Paulo, v. 18, n. 51, p. 103-125, 2004.

FILGUEIRAS, Luiz. 0 neoliberalismo no Brasil: estrutura, dinâmica e ajuste do modelo econômico. In: BASUALDO, Eduardo; ARCEO, Enrique (org.). Neoliberalismo y sectores dominantes: tendencias globales y experiências nacionales. Buenos Aires: CLACSO, 2006. p. 179-206.

FONSECA, Francisco. Mídia, poder e democracia: teoria e práxis dos meios de comunicação. Revista Brasileira de Ciência Política, Brasília, n. 6, p. 41-69, 2011.

FORNERO, Giovanni. Genealogia do Poder. In: ABBRAGNANO, Nicola. Dicionário de filosofia. 5. ed. São Paulo: Martins Fontes, 2007.

FOUCAULT, Michel. A ordem do discurso. 5. ed. São Paulo: Loyola, 1999.

FOUCAULT, Michel. Microfísica do poder. Rio de Janeiro: Graal, 2003.

FOUCAULT, Michel. Nascimento da Biopolítica: curso dado no Collège de France (19771978). São Paulo: Martins Fontes, 2008.

FOUCAULT, Michel. Uma estética da existência. In: FOUCAULT, Michel. Ética, sexualidade, política. Rio de Janeiro: Forense Universitária, 2004. p. 288-293. (Coleção Ditos e escritos, $5)$.

FOUCAULT, Michel. Resposta a uma questão. In: FOUCAULT, Michel. Repensar a política. Rio de Janeiro: Forense Universitária, 2010. p. 1-24.

PEREIRA, Reneé. Empresários comemoram aprovação da reforma trabalhista. Exame, São Paulo, 12 jul. 2017.

PERES, Rodrigo Sanches; SILVA, Juliana Azevedo da; CARVALHO, Ana Maria Rodrigues de. Um olhar psicológico acerca do desemprego e da precariedade das relações de trabalho.

Psicologia, São Paulo, v. 5, n. 1, p. 97-110, 2003.

PERRIN, Fernanda. Veja o que muda para empresários e empregados com a reforma trabalhista. Folha de S. Paulo, São Paulo, 12 jul. 2017.

PERUCCHI, Juliana; TONELI, Maria Juracy Filgueiras. Aspectos políticos da normalização da paternidade pelo discurso jurídico brasileiro. Psicologia Política, São Paulo, v. 15, n. 15, p. 139-156, 2008. 
VEYNE, Paul. Foucault: seu pensamento, sua pessoa. Rio de Janeiro: Civilização Brasileira, 2014.

\title{
The business device, work reform and clases in media statements
}

\begin{abstract}
This article aims to problematize the entrepreneurial device and its struggles, through the analysis of statements and discursive practices published in Brazilian newspapers on the labor reform of 2017. The work was guided by the question as to the operation of this device and its subjective reverberations in relations human beings. The concept of a device is thought and used by authors such as Foucault, Deleuze and Agamben, to reflect a set of heterogeneous elements, involving sayings and nots, in order to organize the socially circulating knowledge / power games. The contributions especially Foucauld and some authors who are studying in the neoliberal context gave the theoretical-methodological contribution to the research. The process of sorting the material happened from the research for news about the labor reform, selecting five that had as main focus the entrepreneurs. Thus, an analysis material containing some enunciative instances and punctuated some interpretations was presented, using, as a tool, the Foucaultian discursive analysis. The statements reveal the place of protagonism and reference for entrepreneurs. The creation of alleged clashes and struggles is clear from the construction of two subject positions: that of social rights and demands and that of competitiveness and market. In short, the entrepreneurial device is delineating itself as the protagonist of the social environment, weakening other consolidated devices, such as the legal one, but without provoking oppositions and opposing strikes, which can produce resistance and new possibilities of existence.
\end{abstract}

\section{Keywords}

Work; Worker; Device; Business; Legal

\section{Autoria para correspondência}

Alyssa Magalhães Prado

alymagalhaes@gmail.com 


\section{Como citar}

PRADO, Alyssa Magalhães; WACHELKE, João; SOUSA, Kátia Menezes. O dispositivo empresarial, a reforma trabalhista e seus embates em enunciados midiáticos. Intexto, Porto Alegre, n. 52, e-89828, jan./dez. 2021. DOI: https://doi.org/10.19132/1807-8583202152.89828

Recebido em 21/01/2019

Aceito em 19/06/2019 